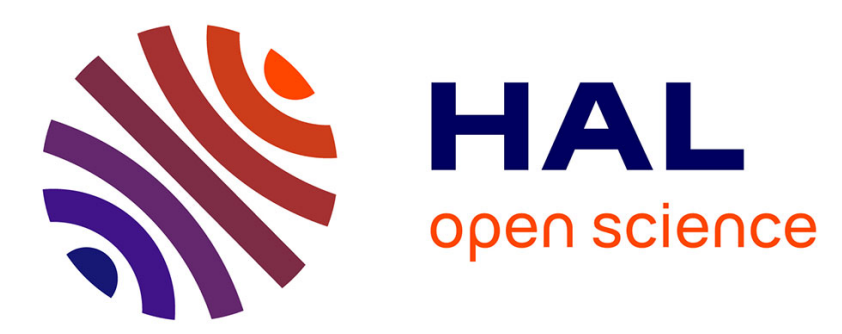

\title{
Impressive Arboreal Gap-Crossing Behaviors in Wild Bonobos, Pan paniscus
}

François Druelle, Peter Aerts, Jean Christophe Bokika Ngawolo, Victor Narat

\section{To cite this version:}

François Druelle, Peter Aerts, Jean Christophe Bokika Ngawolo, Victor Narat. Impressive Arboreal Gap-Crossing Behaviors in Wild Bonobos, Pan paniscus. International Journal of Primatology, 2020, 41 (1), pp.129-140. 10.1007/s10764-020-00140-z . hal-02586931

\section{HAL Id: hal-02586931 https://hal.science/hal-02586931}

Submitted on 30 Nov 2020

HAL is a multi-disciplinary open access archive for the deposit and dissemination of scientific research documents, whether they are published or not. The documents may come from teaching and research institutions in France or abroad, or from public or private research centers.
L'archive ouverte pluridisciplinaire HAL, est destinée au dépôt et à la diffusion de documents scientifiques de niveau recherche, publiés ou non, émanant des établissements d'enseignement et de recherche français ou étrangers, des laboratoires publics ou privés. 


\section{International Journal of Primatology Impressive arboreal gap-crossing behaviours in wild bonobos, Pan paniscus --Manuscript Draft--}

Manuscript Number:

Full Title:

Article Type:

Keywords:

Corresponding Author:

IJOP-D-19-00114R2

Impressive arboreal gap-crossing behaviours in wild bonobos, Pan paniscus

Original Article

Fieldwork; Hominoid; Leaping; Locomotion; Habitat fragmentation

François Druelle, Ph.D.

Muséum National d'Histoire Naturelle

Paris, Île-de-France FRANCE

Corresponding Author Secondary Information:

Corresponding Author's Institution:

Muséum National d'Histoire Naturelle

Corresponding Author's Secondary Institution:

First Author:

François Druelle, Ph.D.

First Author Secondary Information:

Order of Authors:

François Druelle, Ph.D.

Peter Aerts

Jean-Christophe Bokika Ngawoko

Victor Narat

Order of Authors Secondary Information:

Manuscript Region of Origin:

FRANCE

Funding Information:

ONG Mbou Mon Tour

(N/A)

UMR 7206 CNRS MNHN

(N/A)
M. Jean-Christophe Bokika Ngawoko

Dr. Victor Narat

\section{Abstract:}

Most primates are arboreal, and the current context of habitat fragmentation makes gap- and road-crossing behaviours more and more common. Great apes may try to avoid behaviours such as arboreal leaping because such behaviours are risky given their size. Here, we report impressive gap-crossing by wild bonobos, Pan paniscus, in the Democratic Republic of Congo, induced by human disturbance and habitat fragmentation. We quantify the basic mechanics of leaps and arboreal landing performance in 2 individuals. The bonobos climbed a tree, $15 \mathrm{~m}$ high, and performed pronograde leaps between thin flexible branches, to grasp landing branches approximately $4 \mathrm{~m}$ further and below their starting point. They reached an instantaneous velocity of about $9 \mathrm{~m} . \mathrm{s}-1$. The bonobos used pendular swinging of landing branches to dissipate the kinetic energy built up during falling, requiring a grip force of about $2.5 x$ body weight. Moreover, our results show that bonobos might be able to modulate the drag experienced during falling (up to $20 \%$ of body weight) by adjusting their posture. Apparently, bonobos evaluate the structural context to perform the best possible leap and balance the risks against the extra energetic costs involved. Further study of locomotor performance is needed to inform conservation planning, due to the extent of habitat fragmentation due to human activities. 
Title: Impressive arboreal gap-crossing behaviours in wild bonobos, Pan paniscus

\section{François Druelle ${ }^{1,2}$, Peter Aerts ${ }^{2,3}$, Jean Christophe Bokika Ngawoko ${ }^{4}$, Victor Narat ${ }^{5}$}

${ }^{1}$ Histoire Naturelle de I'Homme Préhistorique (UMR 7194 CNRS/MNHN), Paris, France

${ }^{2}$ Functional Morphology Laboratory, University of Antwerp, Antwerp, Belgium

${ }^{3}$ Department of Movement and Sports Sciences, University of Ghent, Gent, Belgium

${ }^{4}$ ONG Mbou-Mon-Tour, Territoire de Bolobo, République Démocratique du Congo

${ }^{5}$ Eco-anthropologie (UMR 7206 CNRS/MNHN/Paris Diderot), Paris, France

Corresponding author: François Druelle, Histoire Naturelle de I'Homme Préhistorique (UMR 7194

CNRS/MNHN), 1 rue René Panhard, 75013, Paris, France; Phone number: 0033625416847;

francois.druelle@mnhn.fr

\section{ACKNOWLEDGMENTS}

We thank Mbou-Mon-Tour staff and especially our field assistants Osa Otsiu Epany and Mozungo Ngofuna. We thank French NGO Bonobo ECO and the Eco-anthropology unit of the CNRS for financial support. We thank the two referees for their constructive and detailed comments on the first version of the manuscript. We are very grateful to the Editor of the International Journal of Primatology, Joanna M. Setchell, who revised the manuscript and improved the English.

Datasets supporting the present work are available from the corresponding author upon request.

Author Contributions: VN conceived the initial part of the study and the methodology, VN and JCBN acquired funding and conducted fieldwork, FD and PA analysed the data, FD wrote the original draft. $\mathrm{PA}$ and $\mathrm{VN}$ reviewed the manuscript and JCBN provided editorial advice.

Conflict of Interest: The authors declare that they have no conflict of interest. 


\title{
Title: Impressive arboreal gap-crossing behaviours in wild bonobos, Pan
} paniscus

Short running title: Arboreal gap-crossing in bonobos

\begin{abstract}
Most primates are arboreal, and the current context of habitat fragmentation makes gap- and roadcrossing behaviours more and more common. Great apes may try to avoid behaviours such as arboreal leaping because such behaviours are risky given their size. Here, we report impressive gap-crossing by wild bonobos, Pan paniscus, in the Democratic Republic of Congo, induced by human disturbance and habitat fragmentation. We quantify the basic mechanics of leaps and arboreal landing performance in 2 individuals. The bonobos climbed a tree, $15 \mathrm{~m}$ high, and performed pronograde leaps between thin flexible branches, to grasp landing branches approximately $4 \mathrm{~m}$ further and below their starting point. They reached an instantaneous velocity of about $9 \mathrm{~m} \cdot \mathrm{s}^{-1}$. The bonobos used pendular swinging of landing branches to dissipate the kinetic energy built up during falling, requiring a grip force of about $2.5 \mathrm{x}$ body weight. Moreover, our results show that bonobos might be able to modulate the drag experienced during falling (up to $20 \%$ of body weight) by adjusting their posture. Apparently, bonobos evaluate the structural context to perform the best possible leap and balance the risks against the extra energetic costs involved. Further study of locomotor performance is needed to inform conservation planning, due to the extent of habitat fragmentation due to human activities.
\end{abstract}

KEY WORDS: Fieldwork, Hominoid, Leaping, Locomotion, Habitat fragmentation 


\section{INTRODUCTION}

Many primates travel in trees, because a substantial amount of their food is located in the arboreal niche (Fleagle 2013; Hunt 2016). This habitat implies discontinuity, variability, compliance and instability of the substrates. Huge horizontal and vertical gaps are very common between trees. To negotiate such obstacles, primates can climb down to the ground, use tree-swaying behaviours, or leap (Channon et al. 2011a; Demes et al. 1995; Thorpe et al. 2007). For instance, orangutans (Pongo spp.) practice cautious suspensory behaviours (Thorpe and Crompton 2006; Thorpe et al. 2007), while other species perform impressive leaping performances, such as gibbons (Hylobates spp., Symphalangus syndactylus) and bonobos (Pan paniscus; e.g. Fan et al. 2013; Fleagle 1976; Scholz et al. 2006; Susman et al. 1980). Gibbons can leap across gaps exceeding $10 \mathrm{~m}$ horizontally when travelling through the forest canopy (Channon et al. 2011b; Fleagle 1976). Bonobos can also perform impressive jumps in the canopy and from the ground (Scholz et al. 2006; Susman et al. 1980). Bonobos are the closest living relatives to humans, but their skills greatly exceed human maximal performance. For instance, bonobos can easily perform squat vertical jumps of $0.7 \mathrm{~m}$, while human Parkour practitioners and top level athletes do not exceed 0.5 m (Grosprêtre and Lepers 2016; Scholz et al. 2006).

The various ways of dealing with the arboreal environment obviously require different amounts of energy and the selection of one way over others could be related to energy-saving strategies (Halsey et al. 2015; Thorpe et al. 2007). The stiffness of the branches, the distance to cross, the number of tree-sways to perform and the mass of the individuals are all important factors in gap crossing strategies (Halsey et al. 2015). Nevertheless, although large primates could save energy by leaping or using tree-swaying, the risk of injury can override the opportunity to save energy (Halsey et al. 2015; Pontzer and Wrangham 2004) and mechanical constraints related to the flexibility of the branches can also limit the locomotor performance, for example (e.g. by reducing power at take-off for leaping; Channon et al. 2011a). In this context, it is commonly suggested that large primates should avoid the most dangerous locomotor behaviours, such as arboreal leaping (Fleagle and Mittermeier 1980; Halsey 
et al. 2015), unless the benefits outweigh the risks, for example, if they need to escape from a conspecific or predator, or to access a particularly rich food site.

Here, we report impressive gap-crossing behaviours in wild bonobos (average body mass is $38 \mathrm{~kg}$ in females and $42 \mathrm{~kg}$ in males according to Druelle et al. 2018) performing a pronograde leap with an extended period of free fall (see Hunt et al. 1996). Using basic mechanics, we quantify the pronograde leap and arboreal landing performance and suggest potential capacities to modulate "falling".

\section{METHODS}

\section{Ethical note}

All research reported in this manuscript adhered to the legal requirements of the Democratic Republic of Congo and is conformed to the Directive 2010/63/EU.

\section{Study site}

We conducted field observations while following the bonobos in the Manzano community (24 individuals under habituation at that time), Bolobo Territory, Democratic Republic of Congo (Narat et al. 2015). This long-term study site is characterized by a fragmented habitat and a forest-savanna mosaic (Pennec et al. 2016). A community-based conservation project led by the Congolese NGO Mbou-Mon-Tour started in the area in 2001. There is large spatial overlap between the bonobo's home range and areas used by humans (Pennec et al. under review).

\section{Data collection}

We present the behaviour of 2 bonobo individuals observed 08:30-09:30 on 14 March 2013 in fragmented habitat. A group of bonobos were travelling on the ground. The first 12 members of the group crossed a dirt road by quadrupedal running and fast walking. A man then passed by on a bicycle, and the rest of the group ( 5 members) climbed a tree (an energetically demanding locomotor mode) and crossed an impressive horizontal and vertical gap above the track by means of a pronograde leap between flexible branches (Figure 1). We estimated the take-off height as $15 \mathrm{~m}$. Furthermore, highly 
flexible branches obviously impede pushing off in a horizontal direction because maximizing power at take-off would create large branch deflection. Thin branches also impede fast running up.

We video recorded the leap made by three individuals (see supplementary material) using a handheld digital camcorder (Canon EOS 600D + objective Canon EF 70-300, frame rates: $25 \mathrm{fps}$ ) at about $80 \mathrm{~m}$ distance. We recorded two of the leaps with the camera fixed and positioned perpendicular to the plane of the leap, making these sequences useful for further analyses. The first leap is performed by a young adult female (Id1) and the second is performed by another adult female carrying an infant ventrally (Id2). The mass of an average female adult is estimated at $38 \mathrm{~kg}$, and the mass of an infant $(\approx 1$ year old) is about $5 \mathrm{~kg}$ (Druelle et al. 2018).

\section{Spatial calibration of the recordings}

To quantify the performance, we calibrated the video frames in the plane of the leap. We used the path of the body centre of mass (BCoM) of Id1 as there is first a brief upwards, then a downwards movement in the free flight part (no contact with the branches) and the vertical velocity equals zero at the apex of the path. We argue that air resistance can be neglected during the first $0.4 \mathrm{~s}$ (i.e., 10 recording frames) of the subsequent free fall (see explanations in the supplementary material). This means that the initial vertical accelerating displacement is only governed by gravity. As a result, the vertical $\mathrm{BCoM}$ displacement $\left(Z_{(t)}\right)$ in video coordinates during these first $0.4 \mathrm{~s}$ should fit a quadratic equation:

$$
Z_{(t)}=a t^{2}+b t+c
$$

where $2 a=a$ monotonous acceleration (video-coordinates $/ \mathrm{s}^{2}$; equivalent to gravitational acceleration), $b=0$ because of the zero vertical speed at the apex, and $c=$ the fitted apex position (in video-coordinates). The spatial scaling factor (SSF) for the sequence of Id1 can thus be determined as the following ratio:

$$
S S F=\frac{-9.81}{2 a}
$$


We approximated the BCoM of Id1 in the recordings as the centre of the trunk and digitized it frame by frame (Geogebra 5.0). The premised fit (using SigmaPlot 11) described the displacement over the 0.4 s interval very well $\left(R^{2}>0.99\right)$, resulting in a highly reliable scaling factor (based on all available data points in the $0.4 \mathrm{~s}$ interval) which we used to convert the video data to real world coordinates. We could not use the same procedure for the Id2-sequence, because the zoom was different and the free fall started with an unknown initial downward speed $(b \neq 0)$. Therefore, we used two non-moving points on the trees to transfer the calibration factor from Id1's sequence to that for Id2.

Leaping performance We digitized the positions of $\mathrm{BCoM}$ for both sequences throughout the pronograde leap, including the arboreal landing phase, and scaled this to the actual positions (displacements) as described in the previous section. We fitted the BCoM displacement in horizontal and vertical directions to quadratic equations (cf. the spatial calibration procedure). We did this for the aerial falling phases when the bonobos had no contact with the trees and the arboreal landing phases, separately. For Id1 the aerial phase started after the calibration period, i.e. when downwards speed exceeds $-3.9 \mathrm{~m} / \mathrm{s}$. For Id 2 the aerial phase started at a similar downward speed. The first derivatives of these equations provide the instantaneous velocities and we used these to calculate the speed at landing (first branch contact). The second derivatives of these equations (single number $=2 a$ ) represent the mean accelerations of the individual during the phases considered. These accelerations can be used in the equations of motion to determine the mean air resistance on the body and the mean 'branch reaction force' during the landing phase, which is equivalent to the grasping force of the animals onto the branches.

In vertical direction these equations are:

Aerial phase: $m a_{V}=m g+F_{\text {resV }}$

Arboreal landing phase: $m a_{V}=m g+F_{\text {resV }}+F_{b r V}$

In horizontal direction: 
Aerial phase: $m a_{H}=F_{\text {resH }}$

Arboreal landing phase: $m a_{H}=F_{r e s H}+F_{b r H}$

with $m=$ body mass, $a_{V, H}=$ observed vertical/horizontal acceleration, $F_{r e s v, H}=$ mean air resistance force and $F_{b r V, H}=$ mean 'branch reaction force'. Knowing the respective accelerations, we can calculate $F_{\text {res }}$ from the aerial phase. Introducing this in the equation of motion for the arboreal landing phase provides $F_{b r}$.

\section{RESULTS}

(a) Negotiating take-off on flexible branches

We estimated the height difference between the take-off and the landing site as $4.3 \mathrm{~m}$ for Id1 and 3.8 $\mathrm{m}$ for Id2, and the horizontal distance to cross as $3.6 \mathrm{~m}$ for Id 1 and $4 \mathrm{~m}$ for Id2. Therefore, the absolute diagonal distance to cross between the flexible branches was $5.6 \mathrm{~m}$ for Id 1 and $5.5 \mathrm{~m}$ for Id2. We observed that bonobos tried to minimise the deflection of the branches before initiating take-off. Id1 grabbed branches above her with one arm, while Id2 walked slowly on the flexible branches, then took a step back and adopted a static crouched posture. The potential waste of energy in deforming the compliant support seems to be limited in both individuals, and there is no visual recoil of the branches before the contact is lost. Furthermore, the angle of take-off can be visually estimated to be about $5^{\circ}$ from the horizontal, suggesting that the leaping force is mainly oriented along the long axis of the branches.

(b) Falling speed and acceleration

The average downwards acceleration is $9.09 \mathrm{~m} . \mathrm{s}^{-2}$ in Id1 and $8.03 \mathrm{~m} \cdot \mathrm{s}^{-2}$ in Id2 (Figure 2). This means that air resistance plays a significant role in these leaping behaviours: $27.4 \mathrm{~N}$ in Id1 and $76.4 \mathrm{~N}$ in Id2 (estimated from the quadratic equations in Figure 2). Horizontal acceleration is negligible (very close to zero).

(c) Landing on flexible branches 
We estimated the instantaneous velocity when the bonobos reached the flexible branches of the landing site at $8.89 \mathrm{~m} \cdot \mathrm{s}^{-1}$ for Id 1 and $8.34 \mathrm{~m} \cdot \mathrm{s}^{-1}$ for Id2. The related kinetic energies are high $(39.5 \mathrm{~J} . \mathrm{kg}$

${ }^{1}$ for Id1 and $34.78{\mathrm{~J} . \mathrm{kg}^{-1}}$ for Id2). These energies need to be dissipated during the landing phase and the grasping forces needed largely depend on the overall deceleration during landing. We estimated the mean downwards deceleration during branch contact as $13.68 \mathrm{~m} \cdot \mathrm{s}^{-2}$ in Id1 and $9.84 \mathrm{~m} \cdot \mathrm{s}^{-2}$ in Id2, and the forward acceleration as $4.05 \mathrm{~m} \cdot \mathrm{s}^{-2}$ in Id 1 and $4.99 \mathrm{~m} \cdot \mathrm{s}^{-2}$ in Id2. This horizontal acceleration is due to kinetic energy transfer related to the bending of the flexible branches that act as a natural pendulum. In other words, the branch reaction force pulls upwards and forwards because of the pendular swing transfer. The total branch reaction force must be "countered" by grasping. We estimated the total mass-specific grasping force exerted on the branches $\left(F_{b r} / \mathrm{m}\right)$ at $26.56 \mathrm{~N}^{\mathrm{kg}} \mathrm{g}^{-1}$ for Id1 and $22.91 \mathrm{~N} . \mathrm{kg}^{-1}$ for Id2, equivalent to about 2.5 times body weight. This is high but feasible. Although we observed some differences between the two individuals, both appear to manage the deflection of the branches perfectly.

\section{DISCUSSION}

We quantify leaping basic mechanics in free-ranging bonobos in the context of forest fragmentation and route decision. First, the bonobos climbed from the ground, which already requiring work of approximately $6 \mathrm{~kJ}$ (mass $\mathrm{x}$ gravity $\mathrm{x}$ height) for $\mathrm{Id} 1$ and $>7 \mathrm{KJ}$ for Id 2 (estimating infant mass as $>5 \mathrm{~kg}$ ). Second, we did not observe pumping behaviours, hence the propulsive forces of branch recoil were not used (Demes et al. 1995; Fleagle 1976). The minimization of branch deflection has also been experimentally tested and observed in gibbons (Channon et al. 2011a), suggesting no use of the energy-storage capability of the flexible substrate at take-off. Third, the difference in $F_{\text {res }}$ for the two similar individuals suggest that the bonobos use postural strategies to influence their surface area during the pronograde leap, therefore controlling their momentum to some extent, as observed in lemurs (see also Dunbar 1988). The fact that Id2 was carrying an infant may be related to important postural modulation, resulting in lower total acceleration and a lower velocity at landing. Arboreal 
locomotion is inherently energetically demanding and risky (Halsey et al. 2015; Pontzer and Wrangham 2004; Thorpe et al. 2007), but our study suggests that the perception of danger (e.g. road $x$ human presence) is a fundamental factor in whether to move on the ground or in the trees. The bonobos studied could correctly evaluate the situation to perform optimal leaps (see Figure 3 for an overview of the road-crossing context). Crossing a considerable horizontal distance as such when the forward propulsive capacities are limited (running up and pushing of thin flexible branches are limited) requires climbing higher. The question remains whether they are able to perform such optimal leaps in every situation encountered.

Bonobos regularly use leaping behaviours in their positional repertoire (Doran 1992) and do so more frequently than chimpanzees (Pan troglodytes; Doran 1992; Doran 1993). Some morphological features may be related to bonobo's enhanced leaping capacities when compared to chimpanzees. For instance, their slightly smaller size, their elongated trunk, their smaller girth and the subtle differences toward longer leg may improve leaping performance (Coolidge and Shea 1982; Druelle et al. 2018; Shea 1984; Zihlman and Cramer 1978). However, studies comparing the morphology of bonobos and chimpanzees are generally limited by small sample sizes and the extent of any differences remains unclear (see Druelle et al. 2018 for an overview) making a straightforward interpretation of leaping adaptation in bonobo difficult.

Bonobos are the heaviest primate for which such impressive leaping behaviours have been reported. Other, lighter, primates perform remarkable leaps in the trees (Table 1). Although the leaping performance of primates has been studied in controlled captive environments (e.g. Channon et al. 2010; Channon et al. 2011b; Demes et al. 1999; Demes et al. 1995), it is difficult to evaluate the maximum locomotor performance of these species in these contexts. Reports from field studies allow us to assess the maximum locomotor performance of primates in their natural habitat. However, given the infrequent nature of these behaviours (primates do not use their maximum performance every day) and the difficulty of measuring the distances animals cover in the trees (commonly estimated by 
eye; Table 1), any information of this kind is very valuable for our understanding of primate locomotor evolution. Methods based on basic mechanics, like those we use, can help to assess the distances and the locomotor performance of primates in the wild.

Table 1. Examples of maximum leaping distances recorded in primates

\begin{tabular}{|c|c|c|c|c|c|c|}
\hline Species & $\begin{array}{l}\text { Leaping } \\
\text { distance } \\
(\mathrm{m})\end{array}$ & $\begin{array}{c}\text { Type of } \\
\text { measure }^{1}\end{array}$ & $\begin{array}{c}\text { Mean } \\
\text { body mass } \\
(\mathrm{kg})^{2}\end{array}$ & Context & Method & Study \\
\hline Semnopithecus priam & 19.8 & Linear & 16.8 & $\begin{array}{c}\text { On a transmission } \\
\text { tower }\end{array}$ & $\begin{array}{c}\text { Estimated from tower } \\
\text { height }\end{array}$ & $\begin{array}{c}\text { Anecdotic report in } \\
\text { National } \\
\text { Geographic }\end{array}$ \\
\hline S. entellus & 12.2 & Linear & 14.3 & Natural environment & Visual estimation & Ripley 1967 \\
\hline Macaca fuscata & 4 & Horizontal & 11 & Natural environment & Visual estimation & $\begin{array}{l}\text { Chatani } 2003 \\
\text { Cannon and }\end{array}$ \\
\hline M. fascicularis & 6 & Gap crossed ${ }^{4}$ & 5.4 & Natural environment & Visual estimation & $\begin{array}{l}\text { Leighton } 1994 \\
\text { Mittermeier and }\end{array}$ \\
\hline Colobus guereza & 10 & Linear & 9.53 & Natural environment & Visual estimation & $\begin{array}{c}\text { Fleagle } 1976 \\
\text { Mittermeier and }\end{array}$ \\
\hline Colobus guereza & 15 & Vertical & 9.53 & Natural environment & Visual estimation & $\begin{array}{c}\text { Fleagle } 1976 \\
\text { Mittermeier and }\end{array}$ \\
\hline Ateles geoffroyi & 10 & Linear & 7.8 & Natural environment & $\begin{array}{c}\text { Visual estimation } \\
\text { Visual estimation based }\end{array}$ & Fleagle 1976 \\
\hline Cebus capucinus & 2.95 & Horizontal & 3.7 & Natural environment & $\begin{array}{c}\text { on body lengths } \\
\text { Visual estimation based }\end{array}$ & Gebo 1992 \\
\hline Alouatta palliata & 2.69 & Horizontal & 7.2 & Natural environment & on body lengths & Gebo 1992 \\
\hline Propithecus diadema & 7 & Linear & 6.05 & Natural environment & Visual estimation & Blanchard 2007 \\
\hline Nomascus leucogenys & 4 & Horizontal & 5.8 & Captivity & Personal observation & Channon et al. 2010 \\
\hline Symphalangus syndactylus & 20 & Vertical & 11.9 & Natural environment & Visual estimation & Fleagle 1976 \\
\hline S. syndactylus & 10 & Horizontal & 11.9 & Natural environment & Visual estimation & $\begin{array}{l}\text { Fleagle } 1976 \\
\text { Channon et al. }\end{array}$ \\
\hline Hylobates lar & 5.2 & Linear & 5.9 & Captivity & Measured (laser) & 2011b \\
\hline Pan paniscus & 5.6 & Linear & 45 & Natural environment & Free fall method & This study \\
\hline P. paniscus & 10 & Linear & 45 & Natural environment & Visual estimation & Susman et al. 1980 \\
\hline P. paniscus & 8 & Horizontal & 45 & Natural environment & Visual estimation & Susman et al. 1980 \\
\hline
\end{tabular}

${ }^{1}$ Distances are estimated horizontally, vertically (drop), or linearly (i.e. the absolute linear distance), between the take-off and the landing site

${ }^{2}$ Values are given for males and are from Fleagle (2013)

3 https://www.nationalgeographic.com/animals/2018/08/langur-monkey-jump-tower-india-news/

${ }^{4}$ Estimate of the length of the gap crossed by the animal

While the recorded behaviours involved adults, a young bonobo spent 30 mins on the flexible branches before leaping (we did not video-record this leap). The young bonobo missed the landing branches and fell to the ground. We noticed no obvious injury as a result of the fall. However, in gibbons, infant deaths have been reported in the context of gap-crossing behaviours (Das et al. 2009). Furthermore, a fall such as the one we observed in the juvenile bonobo could be fatal for an adult because of the larger impact forces. Hence, successful gap-crossing behaviours is more important to adults than to juveniles. This behaviour presumably requires both learning and morphological maturation to be effective, due 
to the work and control of momentum required. Adult bonobos may be able to modulate their fall by changing their posture, while the young individuals still need to learn to do this, as in orangutans (Chappell et al. 2015).

Beyond the interest of these observations for biological (anatomo-functional) studies (e.g. Doran 1993; Druelle et al. 2018; O'Neill et al. 2017; Scholz et al. 2006), the locomotor performances of wild primates are of interest because of the importance of habitat fragmentation due to human activities. The current fragmentation of primate habitats is likely to increase gap-crossing and associated risky behaviours (Junker et al. 2012) and a better understanding of how primates cope with habitat fragmentation is a fundamental topic of research for conservation purposes. Beyond the loss of habitat connectivity, forest fragmentation may increase the risk of falling because attempts to cross gaps can fail. Natural canopy bridges are effective to decrease the consequences of habitat fragmentation (Das et al. 2009). Depending on the socio-cultural context and the species targeted, it is also possible to associate artificial rope bridges with natural canopy bridges, for example in neotropical primates living in peri-urban areas (Lindshield 2016). To reach this objective, it is critical to raise awareness in local people and stakeholders, for example to encourage the maintenance of natural canopy bridges near agricultural fields or along logging roads. A better understanding of the locomotor performance of young and adult individuals should be included and considered in conservation strategies, to limit risky behaviours and their consequences in fragmented habitats.

\section{REFERENCES}

Blanchard ML. 2007. Locomotor behaviour and ecology of three sympatric lemur species in Mantadia National Park, Madagascar: University of Liverpool.

Cannon CH, and Leighton M. 1994. Comparative locomotor ecology of gibbons and macaques: Selection of canopy elements for crossing gaps. American Journal of Physical Anthropology 93(4):505-524.

Channon A, Crompton R, Günther M, D'Août K, and Vereecke E. 2010. The biomechanics of leaping in gibbons. American Journal of Physical Anthropology 143(3):403-416.

Channon AJ, Günther MM, Crompton RH, D'Août K, Preuschoft H, and Vereecke EE. 2011a. The effect of substrate compliance on the biomechanics of gibbon leaps. Journal of Experimental Biology 214(4):687-696.

Channon AJ, Usherwood JR, Crompton RH, Günther MM, and Vereecke EE. 2011b. The extraordinary athletic performance of leaping gibbons. Biology letters 8(1):46-49. 
Chappell J, Phillips AC, Van Noordwijk MA, Setia TM, and Thorpe SK. 2015. The Ontogeny of Gap Crossing Behaviour in Bornean Orangutans (Pongo pygmaeus wurmbii). PloS one 10(7).

Chatani K. 2003. Positional behavior of free-ranging Japanese macaques (Macaca fuscata). Primates 44(1):13-23.

Coolidge HJ, and Shea BT. 1982. External body dimensions of Pan paniscus and Pan troglodytes chimpanzees. Primates 23(2):245-251.

Das J, Biswas J, Bhattacherjee PC, and Rao S. 2009. Canopy bridges: An effective conservation tactic for supporting gibbon populations in forest fragments. In: Whittaker D, and Lappan S, editors. The Gibbons: New Perspectives on Small Ape Socioecology and Population Biology. New York: Springer. p 467-475.

Demes B, Fleagle J, and Jungers W. 1999. Takeoff and landing forces of leaping strepsirhine primates. Journal of Human Evolution 37(2):279-292.

Demes B, Jungers WL, Gross TS, and Fleagle JG. 1995. Kinetics of leaping primates: Influence of substrate orientation and compliance. American Journal of Physical Anthropology 96(4):419429.

Doran DM. 1992. The ontogeny of chimpanzee and pygmy chimpanzee locomotor behavior: a case study of paedomorphism and its behavioral correlates. Journal of Human Evolution 23(2):139-157.

Doran DM. 1993. Comparative locomotor behavior of chimpanzees and bonobos: The influence of morphology on locomotion. American Journal of Physical Anthropology 91(1):83-98.

Druelle F, Schoonaert K, Aerts P, Nauwelaerts S, Stevens JM, and D'Août K. 2018. Segmental morphometrics of bonobos (Pan paniscus): are they really different from chimpanzees (Pan troglodytes)? Journal of Anatomy 233(6):843-853.

Dunbar DC. 1988. Aerial maneuvers of leaping lemurs: The physics of whole-body rotations while airborne. American Journal of Primatology 16(4):291-303.

Fan P, Scott MB, Fei H, and Ma C. 2013. Locomotion behavior of cao vit gibbon (Nomascus nasutus) living in karst forest in Bangliang Nature Reserve, Guangxi, China. Integrative Zoology 8(4):356-364.

Fleagle JG. 1976. Locomotion and Posture of the Malayan Siamang and Implications for Hominoid Evolution. Folia Primatologica 26(4):245-269.

Fleagle JG. 2013. Primate Adaptation and Evolution: 3rd Edn: Academic Press.

Fleagle JG, and Mittermeier RA. 1980. Locomotor behavior, body size, and comparative ecology of seven Surinam monkeys. American Journal of Physical Anthropology 52(3):301-314.

Gebo DL. 1992. Locomotor and postural behavior in Alouatta palliata and Cebus capucinus. American Journal of Primatology 26(4):277-290.

Grosprêtre S, and Lepers R. 2016. Performance characteristics of Parkour practitioners: Who are the traceurs? European journal of sport science 16(5):526-535.

Halsey LG, Coward SR, and Thorpe SK. 2015. Bridging the gap: parkour athletes provide new insights into locomotion energetics of arboreal apes. Biology letters 12(11):20160608.

Hunt KD. 2016. Why are there apes? Evidence for the co-evolution of ape and monkey ecomorphology. Journal of Anatomy 228(4):630-685.

Hunt KD, Cant J, Gebo D, Rose M, Walker S, and Youlatos D. 1996. Standardized descriptions of primate locomotor and postural modes. Primates 37(4):363-387.

Junker J, Blake S, Boesch C, Campbell G, du Toit L, Duvall C, Ekobo A, Etoga G, Galat-Luong A, and Gamys J. 2012. Recent decline in suitable environmental conditions for African great apes. Diversity and Distributions 18(11):1077-1091.

Lindshield SM. 2016. Protecting nonhuman primates in peri-urban environments: A case study of Neotropical monkeys, corridor ecology, and coastal economy in the Caribe Sur of Costa Rica. In: Waller MT, editor. Ethnoprimatology: Primate Conservation in the 21st Century: Springer International Publishing. p 351-369. 
Mittermeier RA, and Fleagle JG. 1976. The locomotor and postural repertoires of Ateles geoffroyi and Colobus guereza, and a reevaluation of the locomotor category semibrachiation. American Journal of Physical Anthropology 45(2):235-255.

Narat V, Pennec F, Simmen B, Ngawolo JCB, and Krief S. 2015. Bonobo habituation in a forestsavanna mosaic habitat: influence of ape species, habitat type, and sociocultural context. Primates 56(4):339-349.

O'Neill MC, Umberger BR, Holowka NB, Larson SG, and Reiser PJ. 2017. Chimpanzee super strength and human skeletal muscle evolution. Proceedings of the National Academy of Sciences 114(28):7343-7348.

Pennec F, Krief S, Hladik A, Lubini Ayingweu C, Bortolamiol S, Bokika Ngawolo J-C, and Narat V. 2016. Floristic and structural vegetation typology of bonobo habitats in a forest-savanna mosaic (Bolobo Territory, DR Congo). Plant Ecology and Evolution 149(2):199-215.

Pontzer $\mathrm{H}$, and Wrangham RW. 2004. Climbing and the daily energy cost of locomotion in wild chimpanzees: implications for hominoid locomotor evolution. Journal of Human Evolution 46(3):315-333.

Ripley S. 1967. The leaping of langurs: A problem in the study of locomotor adaptation. American Journal of Physical Anthropology 26(2):149-170.

Scholz MN, D'Août K, Bobbert MF, and Aerts P. 2006. Vertical jumping performance of bonobo (Pan paniscus) suggests superior muscle properties. Proceedings of the Royal Society B: Biological Sciences 273(1598):2177-2184.

Shea BT. 1984. An allometric perspective on the morphological and evolutionary relationships between pygmy (Pan paniscus) and common (Pan troglodytes) chimpanzees. The pygmy chimpanzee: Springer. $p$ 89-130.

Susman RL, Badrian NL, and Badrian AJ. 1980. Locomotor behavior of Pan paniscus in Zaire. American Journal of Physical Anthropology 53(1):69-80.

Thorpe SKS, and Crompton RH. 2006. Orangutan positional behavior and the nature of arboreal locomotion in Hominoidea. American Journal of Physical Anthropology 131(3):384-401.

Thorpe SKS, Crompton RH, and Alexander RM. 2007. Orangutans use compliant branches to lower the energetic cost of locomotion. Biology letters 3(3):253-256.

Zihlman AL, and Cramer DL. 1978. Skeletal differences between pygmy (Pan paniscus) and common chimpanzees (Pan troglodytes). Folia Primatologica 29(2):86-94.

\section{FIGURE LEGENDS}

Figure 1. Context of the pronograde leap observed in bonobos in DR Congo. (A) The first part of the group crosses the track on the ground. After the passage of a man on the track, (B) the second part of the group climbs up the tree and leaps between flexible branches from the left side to the right. The height of the take-off on the flexible branches has been estimated to be at 15 meters above the ground. The stars indicate the same position in both pictures.

Figure 2. Instantaneous displacement during the pronograde leap of Id1 and Id2. The graphs represent the freefall period for the vertical (A) and horizontal displacements (B) and the landing period with the 
flexible branches for the vertical (C) and horizontal displacements (D) including the respective quadratic equation of the fitted regressions. The blue dot indicates the initiation of the freefall including air resistance. The red dot corresponds to the contact with the flexible branches.

Figure 3. Reconstruction (using 3 pictures) of the road-crossing context studied in free-ranging bonobos. This includes both routes, i.e. moving on the ground (1) and using pronograde leap between flexible branches (2). The illustration framed with the green dashed line shows 8 different frames of an adult female carrying an infant ventrally (Id2) performing the leap. 



\section{Free fall}

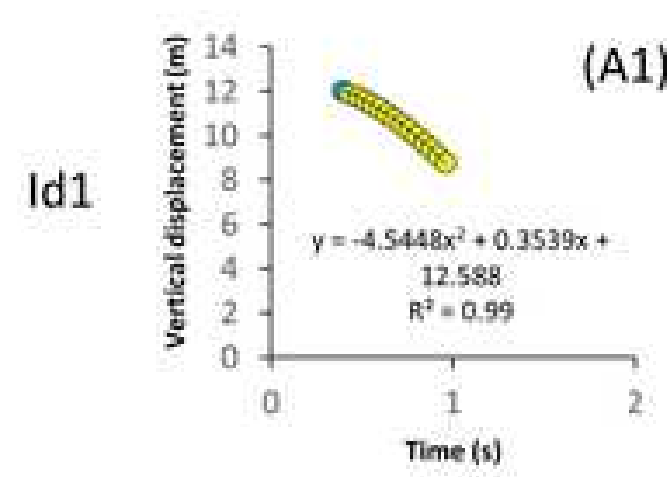

Id 2

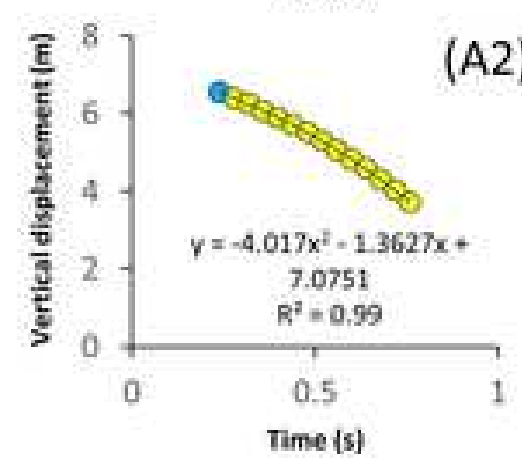

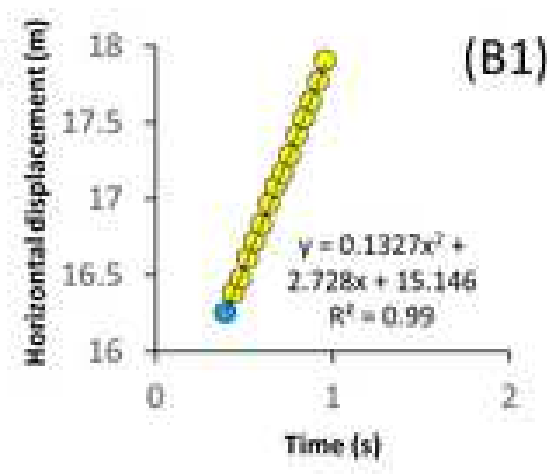

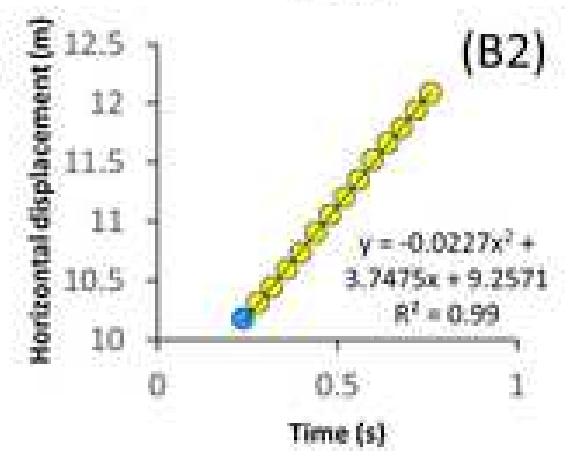

Branch contact
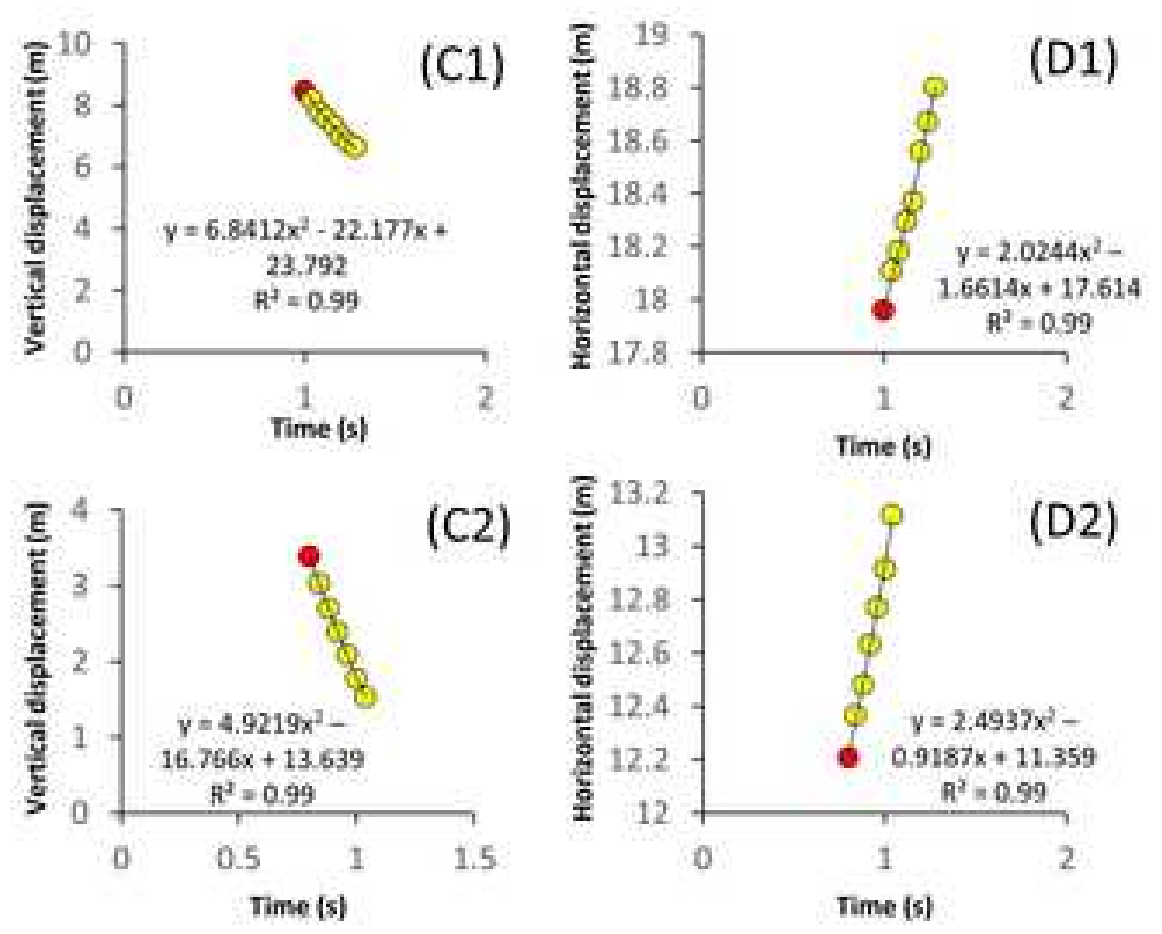


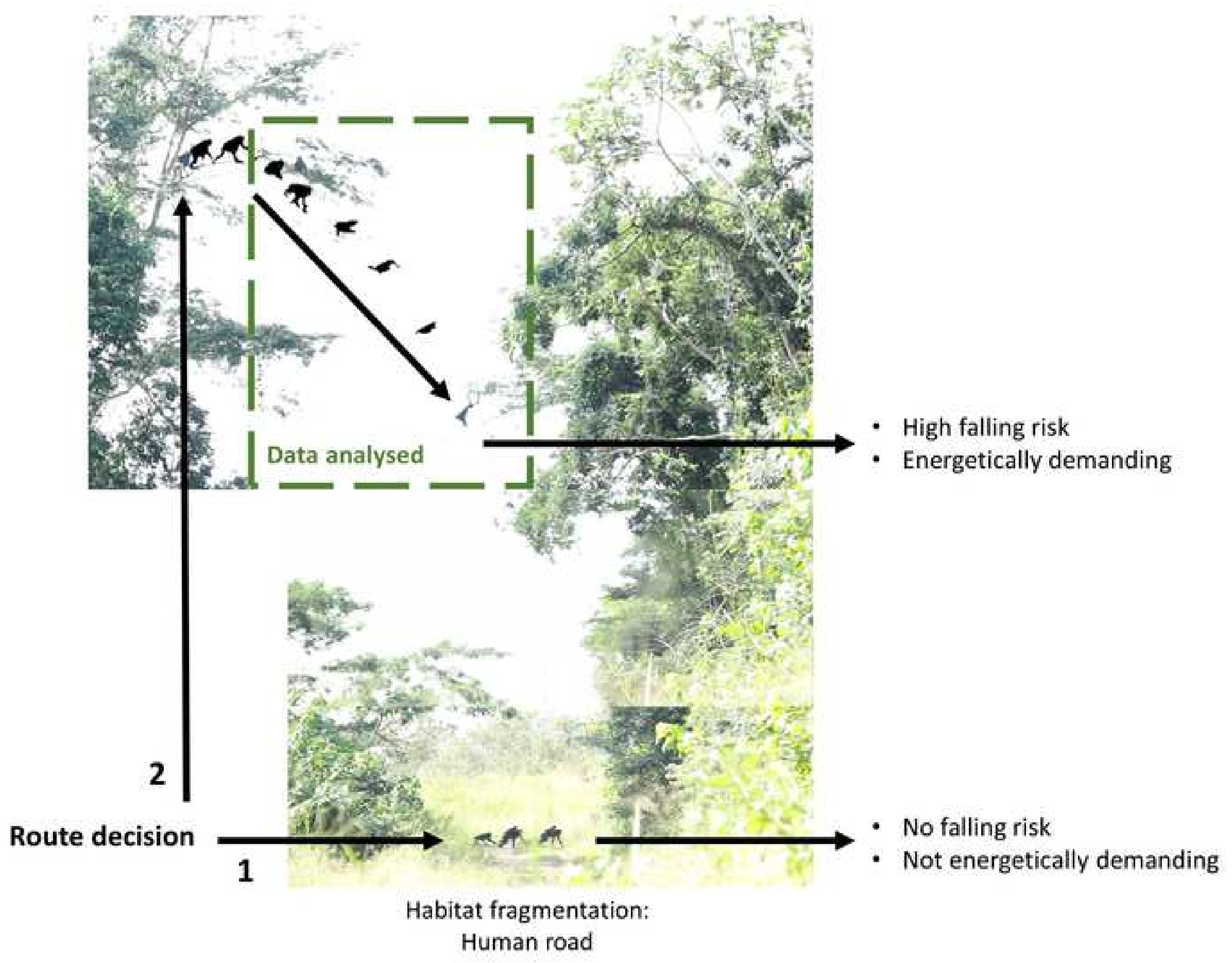


Click here to access/download

Supplemental File Id1.mp4 
Click here to access/download
Supplemental File
Id2.mp4

Click here to access/download
Supplemental File
Id2.mp4 Click here to access/download
Supplemental File
Id2.mp4

(1)

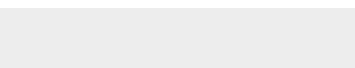

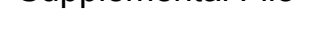

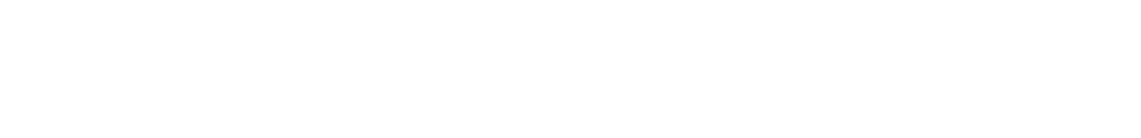

.

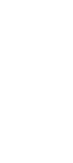

